\title{
Exploring prehospital C2-work during a mass gathering event
}

Erik G. Prytz, Jonas Rybing, Eric Carlström, Amir Khorram-Manesh and Carl-Oscar Jonson

\author{
Linköping University Post Print
}

\section{Tweet}

N.B.: When citing this work, cite the original article.

Original Publication:

Erik G. Prytz, Jonas Rybing, Eric Carlström, Amir Khorram-Manesh and Carl-Oscar Jonson, Exploring prehospital C2-work during a mass gathering event, 2015, International Journal of Emergency Services, (4), 2, 227-241.

http://dx.doi.org/10.1108/IJES-04-2015-0016

Copyright: Emerald

http://www.emeraldinsight.com/

Postprint available at: Linköping University Electronic Press

http://urn.kb.se/resolve?urn=urn:nbn:se:liu:diva-126628 


\section{Article Title Page}

\section{Exploring prehospital C2-work during a mass gathering event}

Author Details (please list these in the order they should appear in the published article)

Author 1 Name: Erik G. Prytz

Department: Department of Computer and Information Science

University/Institution: Linköping University

Town/City: Linköping

State (US only):

Country: Sweden

Author 2 Name: Jonas Rybing

Department: Department of Computer and Information Science

University/Institution: Linköping University

Town/City: Linköping

State (US only):

Country: Sweden

Author 3 Name: Eric Carlström

Department: Institute of Health and Care Sciences

University/Institution: University of Gothenburg

Town/City: Gothenburg

State (US only):

Country: Sweden

Author 4 Name: Amir Khorram-Manesh

Department: Prehospital and Disaster Medicine Centre

University/Institution: Sahlgrenska Academy

Town/City: Gothenburg

State (US only):

Country: Sweden

Author 5 Name: Carl-Oscar Jonson

Department: Centre for Teaching and Research in Disaster Medicine and Traumatology

University/Institution: Linköping University

Town/City: Linköping

State (US only):

Country: Sweden

NOTE: affiliations should appear as the following: Department (if applicable); Institution; City; State (US only); Country. No further information or detail should be included

Corresponding author: Erik G. Prytz

Corresponding Author's Email: erik.prytz@liu.se

Please check this box if you do not wish your email address to be published

\section{Acknowledgments (if applicable):}

Biographical Details (if applicable):

[Author 1 bio]

[Author 2 bio]

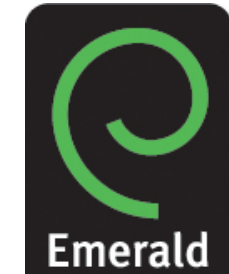

Emerald 
[Author 3 bio]

[Author 4 bio]

\section{Structured Abstract:}

Purpose: The purpose of this study was to explore the workload and shared workload awareness in a staff performing command and control (C2) work during a planned major incident empirical case in Sweden.

Methodology: Data on workload and shared awareness were collected during live C2-work using qualitative observations and insitu interviews mixed with quantitative questionnaires.

Findings: A content analysis of the qualitative data revealed categories of workload sources. Quantified workload estimates showed changes in workload levels over time and staff roles, which were also contextualized using the results of the qualitative data. Data on shared awareness indicated that team workload awareness shifted over time according to common patterns. This study demonstrates a promising methodology to study C2-related factors during live EMS work.

Research implications: The observed variations in workload imply that research that relies only on post-task measurements of workload may be inaccurate. Future research could use this method to investigate the connection between workload and performance during different types of major incidents.

Value: The results can be used to inform future Göteborgsvarvet C2-teams in terms of when, why and for whom task load changes, which would support predictive allocation of resources.

\section{Keywords:}

Emergency Response; Mass gathering; Shared awareness; Mixed methods; Mental workload; Command and control

Article Classification: Research paper

For internal production use only

\section{Running Heads:}

Exploring prehospital command and control 


\title{
Exploring prehospital command and control work during a mass gathering event
}

\begin{abstract}
The purpose of this study was to explore the workload and shared workload awareness in a staff performing command and control (C2) work during a planned major incident empirical case in Sweden. Data on workload and shared awareness were collected during live C2-work using qualitative observations and in-situ interviews mixed with quantitative questionnaires. A content analysis of the qualitative data revealed categories of workload sources. Quantified workload estimates showed changes in workload levels over time and staff roles, which were also contextualized using the results of the qualitative data. Data on shared awareness indicated that team workload awareness shifted over time according to common patterns. This study demonstrates a promising methodology to study C2-related factors during live EMS work. The observed variations in workload imply that research that relies only on post-task measurements of workload may be inaccurate. Future research could use this method to investigate the connection between workload and performance during different types of major incidents. The results can be used to inform future Göteborgsvarvet C2-teams in terms of when, why and for whom task load changes, which would support predictive allocation of resources.
\end{abstract}

\section{Keywords}

Emergency Response; Mass gathering; Shared awareness; Mixed methods; Mental workload; Command and control.

\section{INTRODUCTION}

This paper reports on the results of an empirical field study of the workload sources and levels encountered by a medical prehospital command and control (C2) center during a major mass-gathering event in Sweden in 2014. C2-systems in the pre-hospital domain are part of a larger emergency medical service (EMS) system. EMS systems are defined as systems that "provides for the arrangement of personnel, facilities, and equipment for the effective and coordinated delivery of health care services under emergency conditions" (Moore, 1999). To ensure such "effective" and "coordinated" delivery of health care services, the available resources must be managed appropriately and efficiently. A study by Ruter, Örtenwall, and Wikström (2004) identified that some of the most frequent resource management issues stem from problems with prehospital command and control functions both at a local and regional level. EMS C2-work is therefore a crucial component of the response to Major Incidents (MIs), i.e. events in which available everyday resources are insufficient in relation to the urgent need and which requires emergency resources to be organized and managed differently (Nilsson, 2013; SOSFS, 2005). Failure in the EMS C2-system, i.e. failure to efficiently manage emergency resources, can lead to delay of care, with potential negative patient outcome as the end result (Blackwell and Kaufman, 2002). The primary purpose in the current study was therefore to explore two factors known to influence the performance of C2-systems, namely workload and shared awareness (Berggren et al., 2011; Mathieu et al., 2000).

However, the nature and source of problems related to EMS C2-work are difficult to study in a natural setting during actual work because of the unpredictable nature of incidents that require such work. This has led to some common shortcomings in disaster medicine research as studies often rely on retrospective data collection, are anecdotal in nature, and lack standardized data collection methods (Nilsson, 2013). The current study aimed to overcome these shortcomings by studying aspects of live EMS C2-work during a planned MI. In the Swedish emergency management structure, planned MIs are handled in the same way as MIs 
and rely on the same command structure (Nilsson \& Kristiansson, 2015). The difference is that the term "planned MI" is used for events that are known in advance to require more resources than what is available during normal, everyday work. Examples of planned MIs can be mass gathering events or large-scale vaccination drives such as those that took place in Sweden during the swine-flu pandemic (Berner et al., 2015). Because they are known in advance, the EMS C2-system can be planned and set up with additional resources prior to the event. They also offer an opportunity for planned data collection on aspects of EMS C2-type work in context as they occur rather than retrospectively. The specific C2 aspects studied in the current work were mental workload and shared workload awareness; two factors that are known from previous research to influence the overall performance of C2-systems (Berggren et al., 2011; Berggren et al., 2014).

\section{Workload and shared workload awareness}

According to theoretical models, high workload negatively affects the situational awareness (SA) and teamwork in the C2 system (Berggren et al., 2014). Thus, increased workload may lead to poor SA, and maintaining SA is important for overall performance. However, even though theoretical models of the relationships between these factors have been established in laboratory settings they have not been tested during actual EMS command and control work; the difference between cognition "in captivity" and cognition "in the wild" (see Hutchins, 1995). In part this might be due to the aforementioned difficulty of studying live C2-work as it occurs rather than retrospectively. Existing SA measurement methods in particular have been criticized as inadequate or inappropriate for use in live C2-environments (Salmon et al., 2006) and was therefore not included in this study.

Workload, however, has been studied using validated measurement instruments, such as the NASA Task Load Index (NASA TLX), in many naturalistic settings (see Hart, 2006, for a brief review). Workload commonly refers to the overall experienced load imposed by a performed task and can be defined as "a hypothetical construct that represents the cost incurred by a human operator to achieve a particular level of performance" (Hart and Staveland, 1988, p240). It follows that a higher workload equals a greater cost to the operator to achieve the same level of task performance as during lower workload. This also means that even though two C2-systems performs equally well their exerted workloads, i.e. cognitive resource costs, may differ. It is therefore important to study the workload of EMS C2-systems in action as the performance may suddenly collapse due to prolonged periods of high workload (Hancock and Warm, 1989).

It is also important to consider that the level of workload in real-world tasks is rarely stable over time. Changes in task load, from high to low or low to high, are called workload transitions (Huey and Wickens, 1993) and have been shown to influence both experienced, subjective workload as well as task performance (Helton et al., 2008; Morgan and Hancock, 2011; Prytz and Scerbo, 2014). Furthermore, subjective estimates of workload collected retrospectively, after a task is done, does not capture the transitions between low and high levels that occurred during task performance (Moroney et al., 1995). It is therefore important to measure workload at several time points during task performance to acquire a more accurate picture of the experienced workload.

Another issue in collaborative work is the shared, or mutual, awareness of the workload under which each team member is operating. Essentially, mutual awareness can be defined as "the extent to which team members are informed of other team members' behaviors" (MacMillan, Paley, Entin, and Entin, 2005), for instance concerning workload. One aspect of this is the degree to which team members share the same mental model. A mental model is 
the cognitive structure that reflects an individual's understanding and knowledge of a process or phenomenon. "Shared mental models" is a term used to describe the similar or compatible mental models of members in a well-functioning team (Cannon-Bowers and Salas, 2001). It has been shown that shared mental models are beneficial to team performance (e.g., DeChurch and Mesmer-Magnus, 2010; Mathieu et al., 2000).

\section{The case: Göteborgsvarvet}

The mass gathering event in question was the 2014 Göteborgsvarvet half-marathon, in which over 48000 runners and more than 200000 spectators attended. It is the world's largest halfmarathon. It was also classified as a planned MI by a committee with representatives of the local Gothenburg emergency services. Göteborgsvarvet was so classified because it is a mass gathering event, and mass gathering events have a high likelihood of becoming MIs due to their unpredictable nature and the high strain they impose on the local emergency services (Hines, 2000). A review of 156 articles on mass gathering disasters led Soomaroo and Murray (2012) to conclude that mass gathering events have "an enormous potential to place severe strain on the local health care system" due to high crowd density, restricted points of access, limited crowd control, and lack of sufficient on-site medical care and emergency response.

In the Swedish model, emergency medicine C2 is handled on three different levels: local, regional, and national. The local command structures and coordinates the on-site and individual hospitals' response, regional command coordinates resources and distributes patients and casualties on a regional level (county wide) across multiple hospitals, and national command is concerned with coordinating response to larger cross-county threats (e.g. the forest fire in Västmanland 2014). Prior to the event it was decided that the C2 system responsible for Göteborgsvarvet would be organized at a local level and monitored by a regional level team, and that these two separate C2 teams would be co-located at the Prehospital and Disaster Medicine Center (PKMC; see Khorram-Manesh, Hedelin, and Örtenwall, 2009, for a general description of this center). Many organizations are involved in the C2-work during planned MIs. Beyond the ambulance, police, and rescue services there were also representatives from the event organizers, emergency dispatch, municipal infrastructure office, and the local hospitals. Rescue service established a separate command and control center while retaining a representative at PKMC as a liaison. Together, these organizations formed the collaborative EMS that managed all incidents and accidents, e.g. medical emergencies, traffic management, crimes, and so on, during the Göteborgsvarvet half-marathon. The prehospital resources constituted 14 emergency health care stations staffed with approximately 50 trained health care workers along the running track. Seven of them were equipped with automated external defibrillators mounted on bikes for mobile use. Three ambulances were especially assigned to the half-marathon run, one of them was staffed with a physician specialized in prehospital care.

\section{Research questions}

To study the above presented EMS C2-work aspects, workload and shared awareness, live during the Göteborgsvarvet planned MI both qualitative and quantitative methods were used as a form of mixed methods research (Johnson, Onwuegbuzie, and Turner 2007). Further, four exploratory research questions were posed to guide the study of C2-work. Answering these four questions also served as an initial test of the feasibility of the mixed methodology 
- Research question 1: What general categories of workload sources can be identified during this planned MI?

- $\quad$ Research question 2: What workload levels did EMS workers experience during this planned MI?

- Research question 3: To which extent can observed events (qualitative data) be connected to subjective workload estimates (quantitative data)?

- Research question 4: To which extent were the participating organizations aware of the other organizations' workload?

\section{METHOD}

Previous work on the workload of clinical staff in the emergency department has relied either on only qualitative data (e.g., Mache et al., 2012) or a mix of qualitative and quantitative data (e.g., Levin et al., 2006). Mixed methods was chosen for this study because single methodologies may not provide sufficient data in field studies. For instance, using only a quantitative questionnaire, such as the NASA TLX, does not provide information about what the participant experienced that made them rate their workload in a particular way. This is not a problem for laboratory research as the workload source is typically determined by the researcher, but for research "in the wild" these are essential findings. Thus, one advantage of mixed methods research include that the qualitative data (e.g., observations) can add meaning to quantitative data (e.g., numbers from questionnaires) and the quantitative data adds precision to the qualitative data (Johnson and Onwuegbuzie, 2004). Mixing methods also allow the researcher to answer broader research questions, gain insights and understanding that could otherwise be missed, and produce more complete knowledge to inform theory and practice (Johnson and Onwuegbuzie, 2004). The research design followed the eight-step research model described in Johnson and Onwuegbuzie (2004) and combined quantitative questionnaires with qualitative observations and in-situ interviews. The questionnaires were used to collect data on experienced workload and shared workload awareness. The observations and interviews were used to collect data on performed tasks and occurred events during the C2-work.

\section{Participants}

The participants in the current study were organizational representatives who worked in the EMS C2-team. Representatives participating in the study belonged to the following organizations: rescue services, the event organizers (two representatives), the local hospital, the emergency dispatch organization SOS Alarm, and the emergency health care services (three representatives) for a total of nine participants. All but the organizers had participated in the EMS C2-work at the same event previous years. The following roles participated in the study: the event organization coordinator, the event organization assistant coordinator, the police incident commander, the rescue services representative, the emergency dispatch officer, the staff chief, the medical coordinator, and the local hospital commander.

\section{Questionnaires}

The NASA Task Load Index (NASA TLX; Hart and Staveland, 1988) questionnaire was used to measure subjective workload. The NASA TLX is a well-validated workload questionnaire that has, as of 2006, been used in over 500 studies (Hart, 2006). The questionnaire contains items concerning mental demands, physical demands, temporal demands, performance, effort, and frustration. All of these except physical demands and performance were used in 
the current study. The participants were asked to indicate their workload on each subscale by marking on an $18 \mathrm{~cm}$ long straight line. The line did not display a scale except for a single mark indicating the mid-point of the line. The scales were anchored from "Low" on the left end, and "High" on the right end. To score the questionnaire the distance from the left end to the participant's mark was measured to the nearest $\mathrm{mm}$. This score was divided by the total length in mm and multiplied with 100 to produce a score between 0 and 100 for each subscale. As recommended in Hart and Staveland (1988), these subscales were summed to produce one overall measure of workload that ranged from 0 to 400.

Distributed Assessment of Team Mutual Awareness (DATMA; Macmillan et al., 2004) is a set of subjective questionnaires concerning the shared awareness of workload, tasks, and teamwork. This particular questionnaire was adapted to ask about the overall workload for each organization, rather than individual, in the team. The workload questionnaire was formatted to use the same rating scale system as the NASA TLX. The questionnaire asked the participants to rate their own and every other organization's current workload. That is, for each organization one value between 0 and 100 was produced by averaging the estimates from all representatives that belonged to that organization. This value represented the overall estimated workload for that organization. For each organization, a second value between 0 and 100 was produced by averaging the estimates from all representatives that did not belong to that organization. The estimate by those in the organization was then subtracted from the estimate by those outside the organization to create a discrepancy value. A negative number would indicate that the other organizations underestimated the self-reported workload of that organization. A positive number would indicate that the other organizations overestimated the self-reported value. Larger absolute values indicate larger discrepancy between self-reported workload and the workload perceived by others, i.e. a low awareness of other team organizations' workload.

\section{Procedure}

The participants were briefed about the study and gave informed consent to participate. They were each given an initial questionnaire package and had each questionnaire explained to them. They were told to focus first on their own work and complete the questionnaires if and only if they had the spare attentional capacity and time available to do so. This instruction was to assure that the participants prioritized their own work first. Every hour a research assistant collected the completed questionnaire packages and distributed a new one for a total of five questionnaire packages.

Observations and in-situ interviews were carried out in the control room by two independent and non-participating observers. The observers tracked the activities in the room over time and recorded timestamps whenever possible. One observer was also responsible for administering and collecting the questionnaire packages. No video or audio recordings were collected due to the potentially sensitive nature of the information discussed in the control room. During the work a shift handoff occurred for the rescue services representative and the data reported in the following sections for rescue services representative thus reflects two different individuals.

\section{Command and Control Setup}

The command center consisted of four rooms (see Figure 1). Most of the staff was located in the main area, and those located in the other rooms (A, B, and C) gathered around the conference table in the main area for regular staff meetings. The police was located in room 
A, room B was dedicated radio room for the organizers, and room C was used by the local hospital commander for communication with the hospital. The most central information and communication technology tools are included in Figure 1.

[Figure 1. Spatial layout of command center. Grayed out characters did not participate in the study; dashed characters were not located in the main room but did participate in the study.]

Every 30 minutes the staff gathered around the oval table in the middle of the room, see Figure 1, for a staff meeting. During these staff meetings each role reported on their work situation and what was going on from the point of view of their organization.

\section{RESULTS}

\section{Qualitative analysis}

The qualitative observational data, which includes observed behavior, communication, interviews, and self-reports from staff meetings, were analyzed using a top-down content analysis method in which the data segments were coded for relevance to the C2-aspects of interest, such as events related to workload. First, the entire data set was divided into five time periods, each roughly 1 hour in duration, corresponding to the time when the quantitative questionnaire packages were distributed and collected.

At this stage of analysis the aim was to code all relevant events present in the data set, with no screening for relative importance or frequency of occurrence. With a set of coded events in place, the most prominent or influential event codes in relation to workload, for each role and period of time, were grouped into higher-level categories. For instance, codes such as "heart stop", "fainted runner", and similar were grouped into the higher-level category of "medical emergency", see Table 1. These categories were later mapped onto the quantitative data on workload (see section on Questionnaire results for workload, below). The focus of these categories was events and activities that either involved multiple staff members, such as medical alarms, or that occupied a single staff member for a significant period of time.

\section{[Table 1: Categories of activities contributing to workload]}

An example of one such category is "medical emergency". This category was for instance applied to data describing management of a heart stop that occurred during the race. Below is a passage of data to illustrate a "medical emergency" category case.

At 14:49 a radio call to event organization coordinator reported that a runner had suffered a suspected heart attack. The event organization coordinator called out to the rest of the staff in the room for someone to respond to the alarm. An ambulance alarm was raised by the emergency dispatch officer. A discussion regarding the location of the runner was initiated and event organization coordinator confirmed it to be at the "goal tent" - also known as the "ICU tent". At 14:55 the emergency dispatch officer received a call concerning a runner with suspected heart attack and proceeded to use the emergency dispatch map tool (map monitor 2 in Figure 1) to confirm whether it was the same runner already reported. At the 15:00 staff meeting event organization coordinator was at first too occupied with the high volume of radio communication to attend. The event organization coordinator reported that the volunteers were making way for the ambulances at the goal tent and that this tent was operating under a heavy 
task load. At 15:19 the staff was notified by the local hospital commander that the

heart attack patient had arrived at the local hospital.

During this medical emergency episode between 14:49 and 15:19 the event organization coordinator, event organization assistant coordinator, local hospital commander, staff chief, medical coordinator, and emergency dispatch officer roles have all been engaged, to different degrees, in managing this single event. During the race, two more major medical emergencies, both heart stops, and several minor medical emergencies occurred.

A “race management" category was applied to events and C2-activites directed towards the implementation of the race itself. Such events and activities include resource logistics and management of traffic flow. This category was evident for instance in the work of event organization coordinator and event organization assistant coordinator between 12:00 and 13:30, as they worked to coordinate the field logistics of locating and distributing missing or misplaced resources and equipment (e.g., flags, chairs, volunteer workers, tents, etc.) needed at the stations around the race track. Reports suggested that the volunteers experienced a high workload trying to get everything in order at the last minute. At 13:30, during the first halfhourly staff meeting, the police incident commander reported that street closures and traffic redirection was somewhat challenging as the work was initiated too close in time to the race start. Both these events fall under the race management category. Additional categories include medical resource management, locating geographical points of interest, etc. All categories of observed causes of workload are summarized in table 1 below.

\section{Questionnaire results}

NASA TLX workload scores are available for each individual participant at each of the five time periods, see Table 2. Mapped to the values are the qualitative the categories judged to have had the greatest impact on the workload of each role and for each time period. These categories were not the only sources of workload during each period, and there could be other sources that were not captured in the qualitative analyses. However, based on the qualitative data set these selected categories likely capture the most prominent workload category for each role and time period. For some roles and time periods, no singe particular category was observed to impact that role at that time. These are marked in the table as N/O (None observed). The N/O code should not be interpreted as that the participants were idle during this time, rather it means that no single observed source was considered prominent enough to be mapped onto the workload measurements.

\section{[Table 2: Total workload scores and source for each participant at each time period]}

During one round of questionnaires there were two participants who did not complete the questionnaires (event organization coordinator and event organization assistant coordinator during period 3). These missing values occurred during observed high workload, and the fact that they are missing probably in and of itself indicate high workload. That is, the participants did not complete the questionnaires because they were under a task load greater than any other time when they were able to complete the questionnaires. These missing data points correspond to the period when the first major medical emergency, a heart stop, occurred.

The mixed analysis of subjective workload data from the NASA TLX questionnaire with mapped qualitative categories indicate both how workload shifted in load and source over time for individuals. The DATMA-questionnaire on the other hand measured how the workload of an organization was perceived by other organizations during the EMS work. Table 3 shows a summary of the shared workload awareness score for each organization in the EMS. Negative numbers indicate that the average estimate from all other organizations 
underestimated the workload experienced by that organization. Positive numbers indicate that other organizations overestimated the workload experienced by that organization. For example, the workload of the event organizers (EO) were underestimated by the other organizations (medical, police, emergency dispatch, and rescue services) at period 1 , but overestimated at period 2. At later periods 4 and 5 the other organizations were on average accurate in estimating the workload experienced by the EO.

\section{[Table 3: Shared awareness discrepancy]}

\section{DISCUSSION}

The goal of the current research was to study live collaborative C2-work of an EMS system during a planned MI to understand and measure workload and shared awareness. Four research questions guided the analysis. The first research question asked what workload levels that EMS workers experienced during this planned MI. The results show, as expected, a difference in workload between roles in general. For example, throughout the EMS work, the local hospital commander and the rescue services representative reported a continuous low workload, while the event organization coordinator, on the other hand, continuously reported a relatively high workload. However, most roles reported a variance in their workload over time, often with a decrease during the mid-race period. As different roles in the staff had different responsibilities, these results were expected.

The large variations in workload over time makes it clear that studies that only rely on posttask or retrospective measurements of workload can be misleading for studying C2-work of planned MIs. This is a known shortcoming of most disaster medicine research, as retrospective data collection methods are commonplace (Nilsson, 2013). For such studies there is a risk that changes and transitions in workload during the course of the work will not be captured. The effects of transitions in workload has previously been studied in controlled experiments (e.g., Moroney et al., 1995), where it has been shown that post-task workload measurements depend on both the nature and pattern of changes in task demands. Previous research has also shown that workload transitions can negatively affect performance and experienced stress (Prytz \& Scerbo, 2014). The current study is the first, to our knowledge, to demonstrate workload transitions during actual EMS C2-work. Further exploration on the effects of workload transitions on performance and stress during real EMS C2-work are therefore warranted.

The second research question concerned which general categories of workload sources that could be identified during a live EMS response. Nine categories were observed to affect workload in this study, and the qualitative data analysis revealed that the two medical emergency categories were the most frequently observed causes of workload in the EMS staff. This was expected as medical emergencies, such as runners suffering from exhaustion and dehydration, were anticipated to be the most common cause of response. Thus most of the work in the EMS staff was related to managing those medical responses. The analysis further showed that the event organization personnel, in addition to their main tasks, also were highly engaged in tasks relating to the management of the medical response. This added to their total task load and may explain the high workload levels reported by those roles.

These results related to the third research question, which concerned the extent to which observed events (qualitative data) could be connected to subjective workload estimates (quantitative data). The analysis showed that observed events could be associated with rise and fall of workload. The analysis further showed that one single event could affected the workload of several roles. For instance, the major medical emergencies at period 3 and 5 
greatly affected the event organization coordinator and event organization assistant coordinator, but not others, such as the police incident commander. During the major medical emergency at period 3 the police incident commander reported no significant events and low subjective workload ratings. The police incident commander experienced high workload during period 1 due to the fact that the street closures and traffic redirection were on a tight time schedule. This shows that some sources of workload engaged large parts of the staff and vice versa that some sources could engage single roles without necessarily affecting others.

The last research question asked to which extent the participating organizations were aware of the other organizations' workload. The discrepancy values were overall low, indicating that the workload of each organization was relatively well understood by the other organizations. The semi-hourly staff meetings where each organization reported tasks and events may have contributed to increase the shared workload awareness. However, there are also some patterns of under- and over-estimation that occurred over time as the majority of organizations had their workload overestimated during the mid-race periods 2 and 3 . For example, the police organization was underrated during period 1 and 5 and over-rated during the middle periods. It appears that the other organizations were not aware that the major tasks, and therefore highest workload levels, of the police occurred during periods 1 and 5 with no significant events during periods 2 , 3 , or 4 . This lack of awareness could be related to the fact that the police was located in a room separated from the rest of the staff.

The event organizers were likewise underestimated early on when they were engaged with last-minute logistics in period 1 . Their workload became clearer to the other organizations over time as evident by the fact that the later estimate discrepancies, from periods 4 and 5 , are very small in magnitude. This indicates that the rest of the team became aware of the high load on the event organizers. The increased awareness of the event organizers' workload might be connected to the fact that the sources of workload for the event organizers during the later periods also engaged other roles. Further, medical alarms often came in to the staff via the organizers who shouted out them to the room, leading several staff members to pitch in to help. Thus staff members often gathered by the event organization coordinator workstation to discuss and respond to these events, thus increasing awareness of the workload of the event organizers.

A counterexample is the medical organization and emergency dispatch. Their workload started low and increased over time. However, the shared awareness data seem to indicate that the other team members overestimated the medical organizations' task load initially, but that as the actual workload rose the rest of the team began to underestimate it. In part this could be due to the fact that very few minor medical alarms were openly discussed during staff meetings. Only events in the major emergency category affecting several roles, such as the first heart stop, were discussed by the entire group. This means that most of the work for the medical organizations was not as visible to the other organizations.

These results could be used to make predictive workflows of similar events as the one studied. This could be presented as flowcharts based on the results from previous events. The usefulness of such a flowchart would be an increased shared awareness and appropriate staffing during intense periods of events. Such a flowchart would provide an interorganizational picture of predicted workload during the event and support the allocation of resources.

\section{CONCLUSIONS}


This project aimed to study aspects of collaborative C2 in actual live EMS work during a planned MI, without relying on retrospective or anecdotal data (cf. Nilsson, 2013). A mixed methods approach was used to identify the underlying events that lead to different workload levels during the different time periods of the planned MI, thereby providing a context for interpretation. Contextualization of quantitative data is a known advantage of using a mixedmethods approach (Johnson, Onwuegbuzie, and Turner, 2007), and this study demonstrates the value of using mixed methods during live EMS C2-work by making informative connections between workload levels and observed sources of workload. The main limitation of the method was data loss during periods of extreme workload. Despite this, the results show that EMS C2-work can be studied live without relying on anecdotal data. Further, the variations in workload observed in the current study implies that research that rely only on post-task measurements of workload or shared awareness may be inaccurate because they could fail to capture the fluctuations that take place over time. Future research should use this method to investigate the connection between workload and the resulting effects on performance during different types of major incidents. In conclusion, co-location of the Göteborgsvarvet C2-team created a platform that enabled shared awareness. Major medical emergencies were the major source of workload for many staff functions, but the number of minor emergencies was also important. The results from the current study can be used to inform future Göteborgsvarvet C2-teams in terms of when, why and for whom task load changes, which would support predictive allocation of resources.

\section{ACKNOWLEDGEMENTS}

The authors thank the C2-staff for participating and contributing to this study. Special thanks goes to Per Örninge at PKMC for enabling this study. The research was funded by the Swedish Civil Contingencies Agency (MSB) and the Swedish Institute of Computer Science, East division (SICS East).

\section{REFERENCE LIST}

Berggren, P., Johansson, B., Svensson, E., Baroutsi, N., and Dahlbäck, N. (2014). Statistical modelling of team training in a microworld study. In Proceedings of the Human Factors and Ergonomics Society Annual Meeting, 58, pp. 894-898.

Berggren, P., Prytz, E., Johansson, B., and Nahlinder, S. (2011). The relationship between Workload, Teamwork, Situation Awareness, and Performance in Teams: A microworld study. In Proceedings of the Human Factors and Ergonomics Society Annual Meeting, 55, pp. 851-855. doi:10.1177/1071181311551177

Berner, A., Saleem Alharbi, T., Carlström, E., and Khorram-Manesh, A. (2015). STREET- a Swedish Tool for Risk/Resource Estimation at EvenTs. Part one, risk assessment - face validity and inter-rater reliability. Journal of Acute Disease, published online, pp. 112-116.

Blackwell, T., and Kaufman, J. (2002). Response Time Effectiveness: Comparison of Response Time and Survival in an Urban Emergency Medical Services System. Academic Emergency Medicine, 9(4), pp. 288-295.

Cannon-Bowers, J. A., and Salas, E. (2001). Reflections on shared cognition. Journal of Organizational Behavior, 22(2), pp. 195-202. doi:10.1002/job.82

DeChurch, L. A., and Mesmer-Magnus, J. R. (2010). Measuring shared team mental models: A metaanalysis. Group Dynamics: Theory, Research, and Practice, 14(1), pp. 1-14. doi:10.1037/a0017455

Endsley, M. R. (1995). Toward a Theory of Situation Awareness in Dynamic Systems. Human Factors, 37(1), pp. 32-64. doi:10.1518/001872095779049543

Hancock, P. A., and Warm, J. S. (1989). A Dynamic Model of Stress and Sustained Attention. Human Factors, 31(5), 519-537.

Hart, S. G. (2006). Nasa-Task Load Index (NASA-TLX); 20 Years Later. In Proceedings of the Human Factors and Ergonomics Society Annual Meeting, 50, pp. 904-908. doi:10.1177/154193120605000909 
Hart, S. G., and Staveland, L. E. (1988). Development of NASA-TLX (Task Load Index): Results of Empirical and Theoretical Research. In Hancock, P. A. and Meshkati, N. (Eds.), Human Mental Workload, pp. 239250.

Helton, W. S., Shaw, T. H., Warm, J. S., Matthews, G., and Hancock, P. A. (2008). Effects of warned and unwarned demand transitions on vigilance performance and stress. Anxiety, Stress, and Coping, 21(2), pp. 173-84. doi:10.1080/10615800801911305

Hines, K. (2000). Mass gathering medicine. Trauma, 2, pp. 143-151. doi:10.1191/146040800674209360

Huey, B. M., and Wickens, C. D. (Eds.). (1993). Workload Transition: Implications for Individual and Team Performance. Washington, D.C.: National Academy Press.

Hutchins, E. (1995). Cognition in the Wild. Cambridge, MA: MIT Press.

Johnson, R. B., and Onwuegbuzie, A. J. (2004). Mixed Methods Research: A research paradigm whose time has come. American Educational Research Association, 33, pp. 14-26. doi:10.3102/0013189X033007014

Johnson, R. B., Onwuegbuzie, A. J., and Turner, L. A. (2007). Toward a Definition of Mixed Methods Research. Journal of Mixed Methods Research, 1(2), pp. 112-133. doi:10.1177/1558689806298224

Khorram-Manesh, A., Hedelin, A., and Ortenwall, P. (2009). Regional coordination in medical emergencies and major incidents; plan, execute and teach. Scandinavian Journal of Trauma, Resuscitation and Emergency Medicine, 17, pp. 32-37. doi:10.1186/1757-7241-17-32

Levin, S., France, D. J., Hemphill, R., Jones, I., Chen, K. Y., Rickard, D., ... Aronsky, D. (2006). Tracking Workload in the Emergency Department. Human Factors, 48(3), pp. 526-539. doi:10.1518/001872006778606903

Mache, S., Vitzthum, K., Klapp, B. F., and Groneberg, D. A. (2012). Doctors’ working conditions in emergency care units in Germany: a real-time assessment. Emergency Medicine Journa: EMJ, 29(12), e1. doi:10.1136/emermed-2011-200599

Mathieu, J. E., Heffner, T. S., Goodwin, G. F., Salas, E., and Cannon-Bowers, J. A. (2000). The influence of shared mental models on team process and performance. The Journal of Applied Psychology, 85(2), pp. 273-83.

McMillan, J., Paley, M., Entin, E. B., and Entin, E. E. (2005). Questionnaires for distributed assessment of team mutual awareness. In Stanton, N. A., Hedge, A., Brookhuis, K., Salas, E., and Hendrick, H. (Eds.), Handbook of Human Factors. London: Taylor and Francis.

Moore, L. (1999). Measuring quality and effectiveness of prehospital EMS. In 5th Biannual International Association of Fire Fighters EMS Conference, pp. 325-331, San Francisco, CA.

Morgan, J. F., and Hancock, P. A. (2011). The Effect of Prior Task Loading on Mental Workload: An Example of Hysteresis in Driving. Human Factors, 53(1), pp. 75-86. doi:10.1177/0018720810393505

Moroney, B. W., Warm, J. S., and Dember, W. N. (1995). Effects of Demand Transitions on Vigilance Performance and Perceived Workload. Proceedings of the Human Factors and Ergonomics Society Annual Meeting, 39(21), pp. 1375-1379. doi:10.1177/154193129503902104

Nilsson, H. (2013). Demand for Rapid and Accurate Regional Medical Response at Major Incidents. Ph.D. thesis, Linköping University.

Nilsson, H., and Kristiansson, T. (2015). Katastrofmedicinsk beredskap - att leda sjukvård på ett särskilt sätt. Lund: Studentlitteratur.

Prytz, E., and Scerbo, M. W. (2014). The Effects of a Workload Transition on Stress over Time. In Proceedings of the Human Factors and Ergonomics Society Annual Meeting, 58, pp. 1766-1770. doi:10.1177/1541931214581368

Ruter, A., Örtenwall, P., and Wikström, T. (2004). Performance Indicators for Major Incident Medical Management - A Possible Tool for Quality Control? International Journal of Disaster Medicine, 2, pp. 52-55.

Salmon, P., Stanton, N. A., Walker, G., and Green, D. (2006). Situation Awareness Measurement: A review of applicability for C4i environments. Applied Ergonomics, 37(2), pp. 225-238.

Soomaroo, L., and Murray, V. (2012). Disasters at Mass Gatherings: Lessons from History. PLoS Currents, 4. doi:10.1371/currents.RRN1301

The National Board of Health and Welfare (Socialstyrelsen) (2005). SOSFS 2005:13 (M). Föreskrifter och allmänna råd. Fredstida katastrofmedicinsk beredskap och planläggning inför höjd beredskap [eng. SOSFS 2005:13 (M). Regulations and general advice. Peacetime disaster medicine preparedness and planning for major incidents], Grafikerna Livréna: Kungälv, Sweden. 


\section{Table 1: Categories of activities contributing to workload}

\begin{tabular}{l} 
Category \\
\hline Race management \\
Major medical emergency \\
Minor medical emergency \\
Medical resource \\
management \\
Other emergency \\
Equipment failures \\
Interpreting field reports \\
Maintaining awareness and \\
projecting future status \\
Media management
\end{tabular}

\section{Description}

Tasks related to managing the race, e.g. closing down streets, tracking runners, closing the race, and coordinating resources.

Management of medical emergencies that required response from multiple staff members, e.g. heart attacks.

Management of less severe medical emergencies, requiring the attention of one or a few staff members, e.g. dehydrated runners.

Activities involving managing medical resources, e.g. coordinating medical alarms, ambulances, and resources.

Managing non-medical events requiring response and coordination, e.g. oil spill.

Dealing with events where equipment used by the staff that impeded C2 work, e.g. radio failures.

C2-activities related to interpreting information coming in from the field, often involving discussion of where events were taking place, e.g. ambiguous use of tent-names.

Activities involving media monitoring, anticipation and preparation for work to come.

Contact with reporters and media.

Table 2: Total workload scores and source for each participant at each time period

\begin{tabular}{cccccc} 
& Period 1 & Period 2 & Period 3 & Period 4 & Period 5 \\
\cline { 2 - 5 } TLX & 349.5 & 183.2 & $*$ & 169.4 & 270.5
\end{tabular}

\begin{tabular}{|c|c|c|c|c|c|c|}
\hline EOC & Source & $\begin{array}{c}\text { Race } \\
\text { management }\end{array}$ & $\mathrm{N} / \mathrm{O}$ & $\begin{array}{l}\text { Major medical } \\
\text { emergency }\end{array}$ & $\begin{array}{l}\text { Minor medical } \\
\text { emergency }\end{array}$ & $\begin{array}{c}\text { Major medical } \\
\text { emergency }\end{array}$ \\
\hline & TLX & 222.4 & 62.4 & * & 45.6 & 50.5 \\
\hline EOA & Source & $\begin{array}{c}\text { Race } \\
\text { management }\end{array}$ & $\mathrm{N} / \mathrm{O}$ & $\begin{array}{l}\text { Major medical } \\
\text { emergency }\end{array}$ & $\begin{array}{c}\text { Race } \\
\text { management }\end{array}$ & $\begin{array}{c}\text { Race } \\
\text { management }\end{array}$ \\
\hline & TLX & 16 & 23.9 & 16 & 18.8 & 22.8 \\
\hline IC & Source & $\mathrm{N} / \mathrm{O}$ & $\mathrm{N} / \mathrm{O}$ & $\begin{array}{l}\text { Major medical } \\
\text { emergency }\end{array}$ & N/O & $\begin{array}{c}\text { Major medical } \\
\text { emergency }\end{array}$ \\
\hline & TLX & 22.2 & 18.9 & 42.8 & 41.1 & 36 \\
\hline RS & Source & $\begin{array}{c}\text { Other } \\
\text { emergency }\end{array}$ & $\begin{array}{c}\text { Other } \\
\text { emergency }\end{array}$ & $\mathrm{N} / \mathrm{O}$ & N/O & N/O \\
\hline & TLX & 91.1 & 16.6 & 22.9 & 26.7 & 118.8 \\
\hline PIC & Source & $\begin{array}{c}\text { Race } \\
\text { management }\end{array}$ & $\mathrm{N} / \mathrm{O}$ & $\mathrm{N} / \mathrm{O}$ & $\begin{array}{c}\text { Race } \\
\text { management }\end{array}$ & $\begin{array}{c}\text { Race } \\
\text { management }\end{array}$ \\
\hline MC & TLX & 28.4 & 32.8 & 77.2 & 137.7 & 123.9 \\
\hline
\end{tabular}




\begin{tabular}{|c|c|c|c|c|c|c|}
\hline & Source & $\mathrm{N} / \mathrm{O}$ & N/O & $\begin{array}{c}\text { Major medical } \\
\text { emergency }\end{array}$ & $\begin{array}{c}\text { Medical } \\
\text { resource } \\
\text { management }\end{array}$ & $\begin{array}{c}\text { Major medica } \\
\text { emergency }\end{array}$ \\
\hline & TLX & 107.8 & 41.1 & 26.2 & 87.2 & 34 \\
\hline SC & Source & $\mathrm{N} / \mathrm{O}$ & $\mathrm{N} / \mathrm{O}$ & $\begin{array}{l}\text { Medical } \\
\text { resource } \\
\text { management }\end{array}$ & N/O & $\begin{array}{c}\text { Major medica } \\
\text { emergency }\end{array}$ \\
\hline & TLX & 6.1 & 27.8 & 27.8 & 139.4 & 155 \\
\hline EDO & Source & $\mathrm{N} / \mathrm{O}$ & $\mathrm{N} / \mathrm{O}$ & $\begin{array}{c}\text { Major medical } \\
\text { emergency }\end{array}$ & $\begin{array}{c}\text { Medical } \\
\text { resource } \\
\text { management }\end{array}$ & $\begin{array}{c}\text { Major medica } \\
\text { emergency }\end{array}$ \\
\hline
\end{tabular}

Note: The RS-scores were given by two different participants (participant 1 at periods 1 and 2, participant 2 at periods 3-5). *Missing values. N/O = None observed. Acronyms: Event Organization Coordinator (EOC), the Event Organization Assistant coordinator (EOA), the Police Incident Commander (PIC), the Rescue Services representative (RS), the Emergency Dispatch Officer (EDO), the Staff Chief (SC), the Medical Coordinator (MC), and the Local Hospital Commander (LHC).

Table 3: Shared awareness discrepancy

\begin{tabular}{cccccc} 
& Period 1 & Period 2 & Period 3 & Period 4 & Period 5 \\
\cline { 2 - 6 } EO & $-18,52$ & 31,65 & $*$ & 0,80 & 0,27 \\
MO & 5,85 & 24,34 & 14,72 & 4,98 & $-22,48$ \\
PO & $-19,22$ & 27,02 & 12,33 & 18,01 & $-13,86$ \\
RS & 1,96 & 12,77 & $-7,24$ & 4,10 & 7,16 \\
ED & 7,80 & 15,82 & 8,75 & $-9,49$ & 19,57 \\
Entire staff & 1,04 & 10,61 & 7,78 & $-5,21$ & $-12,49$
\end{tabular}

Note: The values may range from a min of -100 to a max of +100 . The organizations were the Event Organizers (EO), the Medical Organizations (MO), the Police Organization (PO), the Rescue Services (RS), and the Emergency Dispatch (ED). The overall category was a separate question on the questionnaire that concerned the overall workload of the entire staff. *Missing values. 


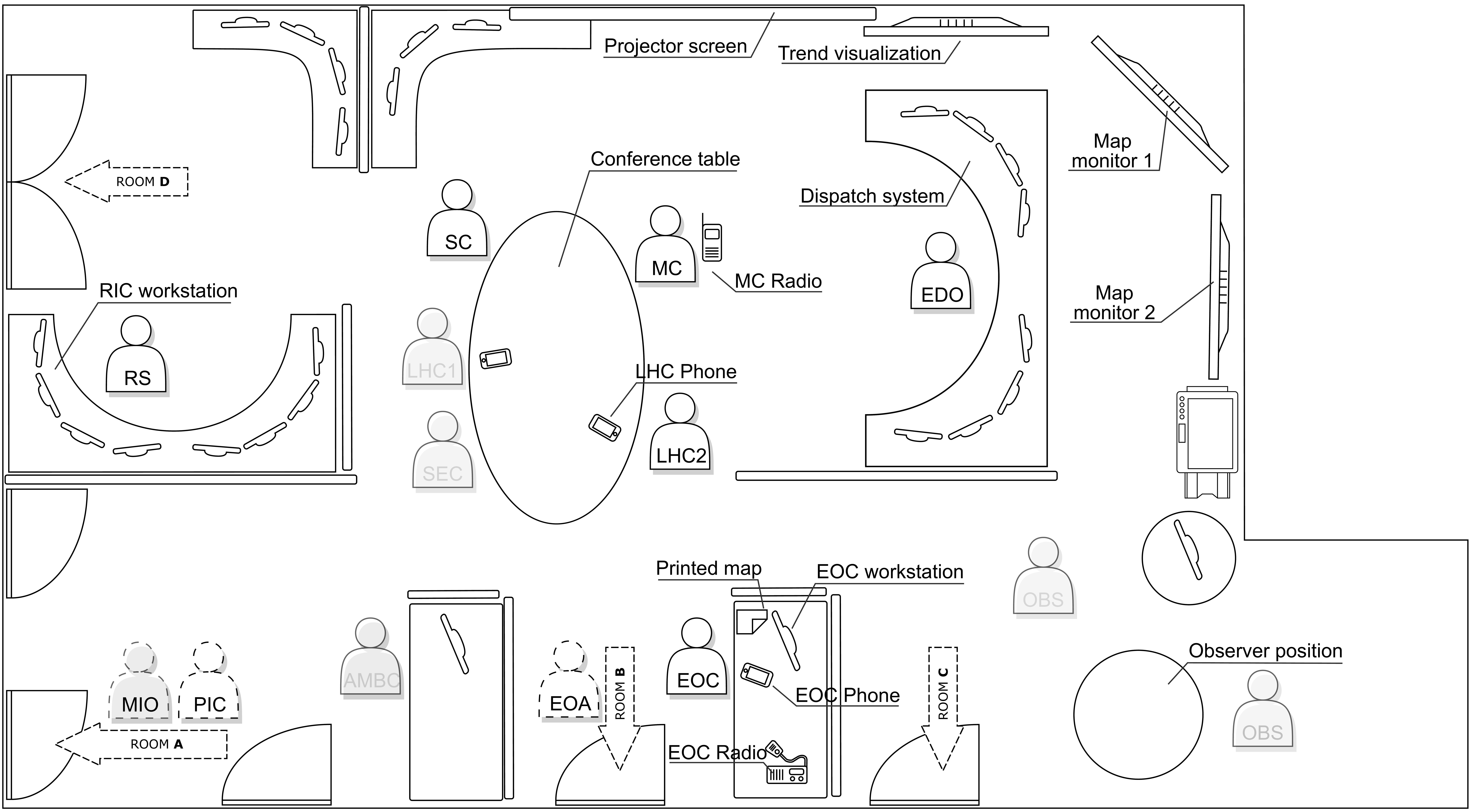

